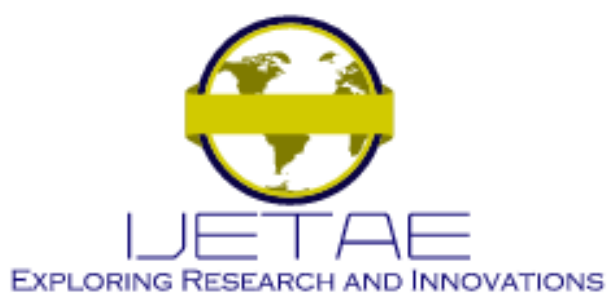

International Journal of Emerging Technology and Advanced Engineering

Website: www.jjetae.com (E-ISSN 2250-2459, Scopus Indexed, ISO 9001:2008 Certified Journal, Volume 11, Issue 11, November 2021)

Manuscript Received: 01 October 2021, Received in Revised form: 29 October2021, Accepted: 05 November 2021

DOI: 10.46338/ijetae1121_09

\title{
Use of Artificial Intelligence for Face Detection with Face Mask in Real Time to Control the Entrance to an Entity
}

\author{
Enrique Lee Huamaní ${ }^{1}$, Lilian Ocares-Cunyarachi ${ }^{2}$ \\ ${ }^{1,2}$ Image Processing Research Laboratory, Universidad de Ciencias y Humanidades, Lima Perú
}

\begin{abstract}
Due to the pandemic caused by Covid-19, daily life has changed significantly. For this reason, biosecurity measures have been implemented to prevent the spread of the virus as an effective way to reactivate economic activities. In this sense, the present paper focuses on real-time face detection as a measure of control at the entrance to an entity, thus avoiding the spread of the virus while recognizing the identity of workers despite the use of masks and thus reducing the risk of entry of individuals outside the organization. Therefore, the objective is to contribute to the security of a company through the application of machine learning methodology. The selection of methodology is justified due to the adaptation of the same according to the interests of this project. Consequently, algorithms were used in a progressive manner, obtaining as a result the control system that was intended, since each particularity of the face of the individual was recognized in relation to its corresponding identification. Finally, the results of this article benefit the security of organizations regardless of their field or sector.
\end{abstract}

Keywords - Control, Detection, Facial Recognition, Facial Mask, Face recognition, Machine learning.

\section{INTRODUCTION}

At the end of 2019, an infectious outbreak of a highly contagious virus was reported in Wuhan, China [1]. After the pertinent studies, it was identified as a new coronavirus known as SARS-CoV-2, which, given its high level of propagation, spread worldwide causing the onset of a pandemic wave [2].

The virus that causes Covid-19 is transmitted mainly by droplets when they are generated by an infected person when coughing or sneezing [3]. These droplets are heavy enough to remain suspended in the air and fall quickly to the ground, so we can become infected by breathing in the virus if we are near a person with Covid-19 as well as by touching a contaminated area. Therefore, we should avoid touching our eyes, nose or mouth to prevent this virus [4].
Patients with SARS-CoV-2 infection were found with signs of lesions ranging from mild to severe, considering also the existence of asymptomatic carriers of the virus. Studies indicate that the most frequent symptoms are fever $83 \%$, cough with $82 \%$ while complexity to breathe has $31 \%$ [5]. Patients with coronavirus demonstrate a decrease in lymphocytes and eosinophils, which causes their hemoglobin to drop [6]. Increases in leukocyte counts, neutrophils and serum levels have also been found in patients with Covid-19 [7].

The competent authorities have imposed general organizational management measures based on the epidemiological emergency of COVID-19; thus, to return to the workplaces, corresponding safety measures were taken. Therefore, the organizational preventive and protective organizational measures aim to minimize the probability of being exposed to Covid-19 [8].

The importance of the research work focuses on being able to identify people working in a company in such a way that, upon entry, the face of authorized personnel is recognized in order to provide greater security. The reason for this is that the use of masks is mandatory as a preventive measure; however, this makes it difficult to ensure the safety and control of those entering an organization. Therefore, the most appropriate way for its implementation is using one of the branches of artificial intelligence known as Machine Learning, which has as its main function to use images or videos to learn the faces of people who use the biosecurity mask so that people can be identified at more than $80 \%$ of assertiveness when the user can show his face for entry [9].

The objective of the research is to help society by providing greater accuracy in the identification of authorized persons for entry control to an entity through face detection even when the individual to be identified is wearing a face mask. 


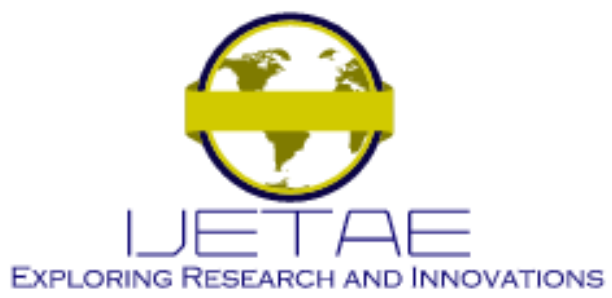

International Journal of Emerging Technology and Advanced Engineering Website: www.ijetae.com (E-ISSN 2250-2459, Scopus Indexed, ISO 9001:2008 Certified Journal, Volume 11, Issue 11, November 2021)

This paper is structured as follows; section II will describe in detail the methodology. Section III will show the case study, section IV will show the results and discussion and finally, section $\mathrm{V}$ will present the conclusions.

\section{MATERIAL AND METHODS}

Machine Learning is a method of data analysis that automates the construction of analytical models and creates systems that learn automatically thanks to artificial intelligence. The machine that actually learns is an algorithm that examines the data and is able to guess future behaviors. Automatically, moreover in this environment, it involves that such systems are improved autonomously with the era, without human involvement. Let's see how it works. The subfield of Artificial Intelligence called Machine Learning is an area of study that provides tools that allow using a large amount of data to select different sampling similarities from the collected data can make predictions and give us numbers to control the decisionmaking process. This work presents this vision, applying an algorithm on the data based on the security of the data [10]. In Fig. 1 it is observed as the first step we collect and process the data, as a second step we create the required model, in the third step we capture the faces so that in step 4 they are trained and in step 5 they are evaluated in detail and finally we obtain the results applied with machine learning, next we will explain the steps in detail.

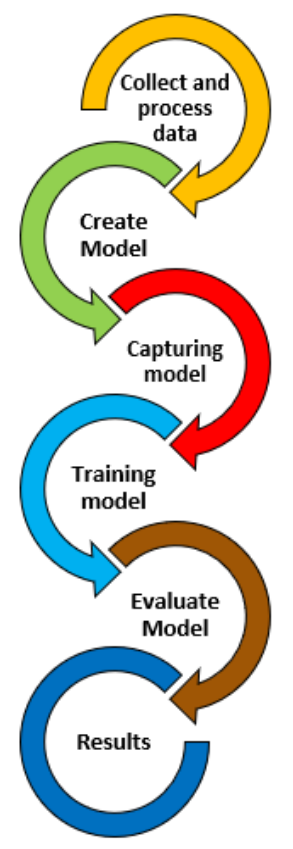

Fig. 1. Implementation of Machine Learning phases

\section{A. Machine Learning Phases}

In the first phase we defined the amount and type of data, here we collected all the data and information necessary to carry out the project, and we investigated in detail the tools to be used in such a way that we processed all the information collected for a good result [11]. 


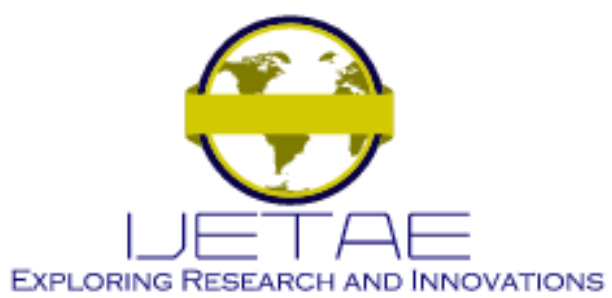

International Journal of Emerging Technology and Advanced Engineering Website: www.ijetae.com (E-ISSN 2250-2459, Scopus Indexed, ISO 9001:2008 Certified Journal, Volume 11, Issue 11, November 2021)

1) Create Model: The second phase is where we can create a model, according to the objective we have, where we will use all the information of the data mentioned in the first phase, we begin to create the algorithms for the realization of the project and thus be able to reach an ideal model [12].

2) Capturing Model: In the third phase, we capture the model based on the algorithms used to obtain a good performance with respect to model capture [13].

3) Training model: The third phase is dedicated to the training of the model, where we will use all the data to run it, in this phase all the data must be verified properly detailed in order to obtain satisfactory results [14].

4) Evaluate model: In this stage the chosen model is evaluated, on the one hand, the data processing and the training data model are shown, for which all the data of the chosen model are attached to forecast new results [15].

5) Results: In this last phase, all the results obtained from the model based on machine learning techniques will be obtained in detail.

\section{CASE STUDY}

\section{A. Collect and process data}

In the first phase we collect data to then be processed in this case by applying machine learning, therefore in this first phase will identify important and essential data for the realization of the identification of the face [16].

In Fig. 2 we can see that we imported the cv2, os, data and finally numpy as $\mathrm{np}$, to import the corresponding libraries, we call the address where the file is located then we tell it to call the people list where its corresponding parameters are defined to return the digit, then we enter the code for nameDir in peoplelist means that we call the person with its designated name in such a way that it is processing the people to return the result [17].

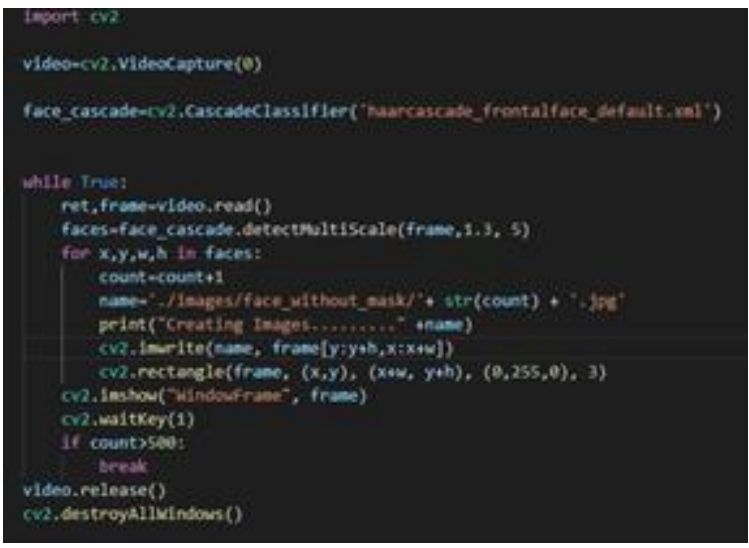

Fig. 2. Collect and process data

Table I describes the most important tools of the project on face detection with face mask, describes in detail the development in Python, and the libraries to be used as open $\mathrm{cv}$ and numpy that complement the system with tensor flow.

TABLE I

TOOLS USED

\begin{tabular}{|l|l|}
\hline \multicolumn{2}{|c|}{ Tools used } \\
\hline Python & $\begin{array}{l}\text { Python is an interpreted programming } \\
\text { language whose philosophy emphasizes the } \\
\text { readability of its code. It is a multi-paradigm } \\
\text { programming language, since it partially } \\
\text { supports object-oriented and imperative } \\
\text { programming [18]. }\end{array}$ \\
\hline Tensor Flow & $\begin{array}{l}\text { TensorFlow is an open source machine } \\
\text { learning library for a range of machine } \\
\text { learning tasks, developed by Google to solve } \\
\text { their needs for systems capable of building } \\
\text { and running neural networks to identify and } \\
\text { decipher patterns. }\end{array}$ \\
\hline Open Cv & $\begin{array}{l}\text { It is an independent library of artificial } \\
\text { perspective originally discovered by Intel, in } \\
\text { the library you find an infinite number of } \\
\text { codes in which it is a tool that facilitates the } \\
\text { process. }\end{array}$ \\
\hline Numpy & $\begin{array}{l}\text { NumPy is a library dedicated to the Python } \\
\text { programming language which supports the } \\
\text { generation of vectors and multidimensional } \\
\text { arrays,thus playing a huge role in the } \\
\text { collection of functionalities. }\end{array}$ \\
\hline
\end{tabular}




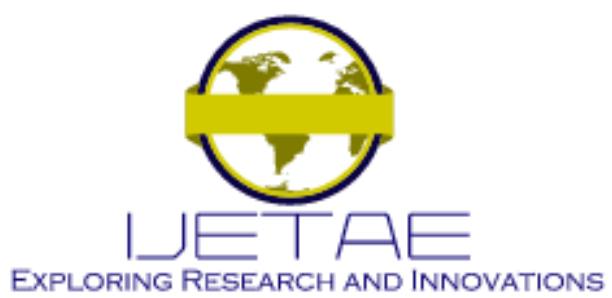

\section{International Journal of Emerging Technology and Advanced Engineering}

Website: www.ijetae.com (E-ISSN 2250-2459, Scopus Indexed, ISO 9001:2008 Certified Journal, Volume 11, Issue 11, November 2021)

\section{B. Create model}

In the second phase we apply the data obtained and processed from phase 1 to create the required model, creating algorithms that will lead us on the right path [19].

In Fig.3 shows the model created with the most prominent code Face $=$ faceclassif.detectMultiscale (gray 1, $3,5)$ from that precise moment begins to identify the face of the person stored in a parameter if $\mathrm{k}==27$ or count $=$ 300; break where it will return 300 images identifying the face if more images are required it will only change the number of specific digit [20].

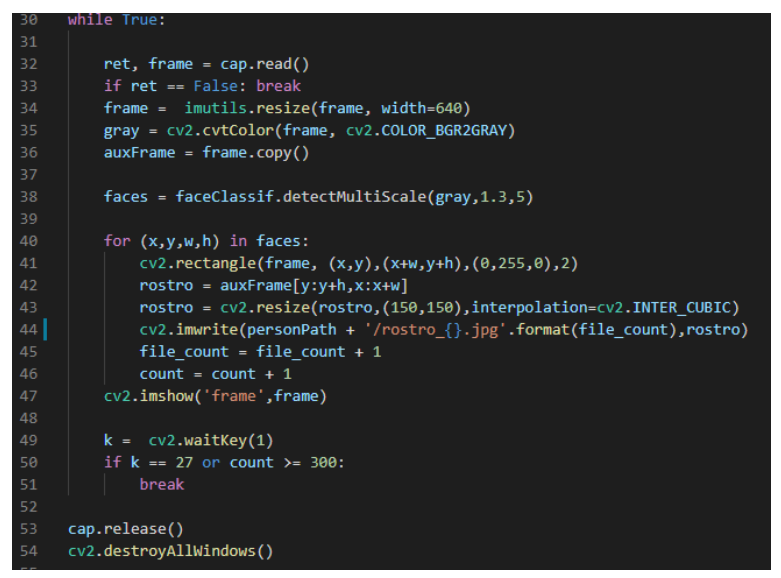

Fig. 3. Create Model

\section{Capturing model}

In the third phase we capture the faces identified in the system through facial recognition, in this phase we obtain a precise identification of the face and manage to identify and capture the face.

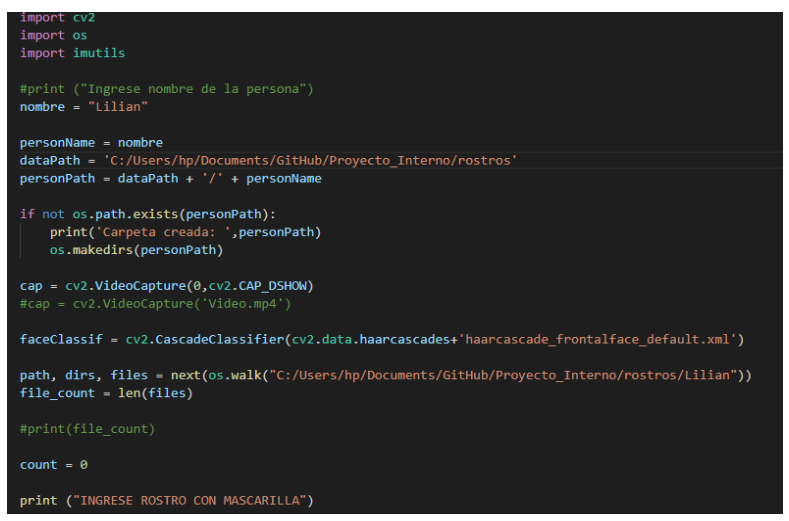

Fig. 4. Code capturing the face
In Fig.4 it is shown the capture of the faces once identified it goes to the capture of all the captured images where when saving it returns an xml file, declared faceclassif $=$

cv2.cascadeclassifier(cv2, data.haarscascade+'haarscascadefrontalface-default.xml' then it will print us Ingress face with mask.

\section{Training model}

In the fourth phase we train all the captured data mentioned in the third phase, when training each face obtained we identify each one of the identified faces with a small size centered on the facial expressions, when trained we return each image with its corresponding number in this case we specify the system with a parameter observed in the following figure [21].

In Fig. 5 shows how the model, after being captured, is trained by defining each person with a digit so that when the person is identified, the model can recognize him/her by name.

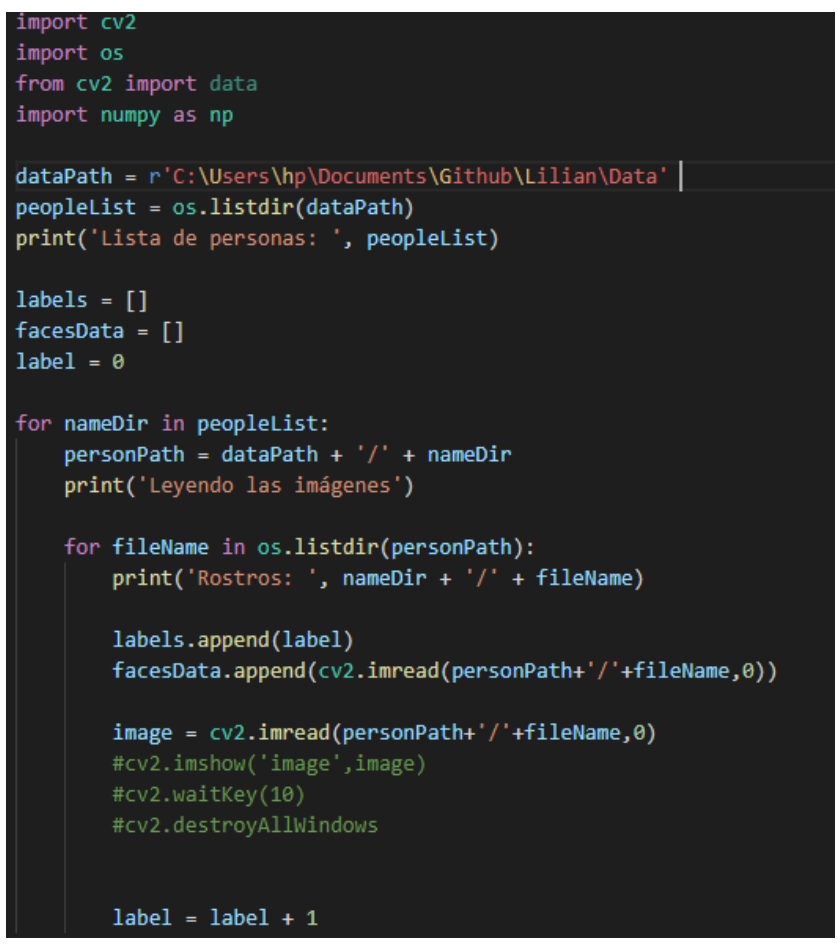

Fig. 5. Training the model 


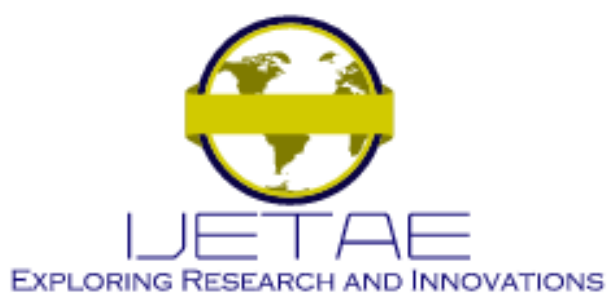

International Journal of Emerging Technology and Advanced Engineering

Website: www.ijetae.com (E-ISSN 2250-2459, Scopus Indexed, ISO 9001:2008 Certified Journal, Volume 11, Issue 11, November 2021)

In Fig.6 shows the code returned by the system that is automatically generated when the model is captured and automatically saved so that it can have a good performance capturing the faces of the different people using the facial recognition system since in an entity there are different working personnel.

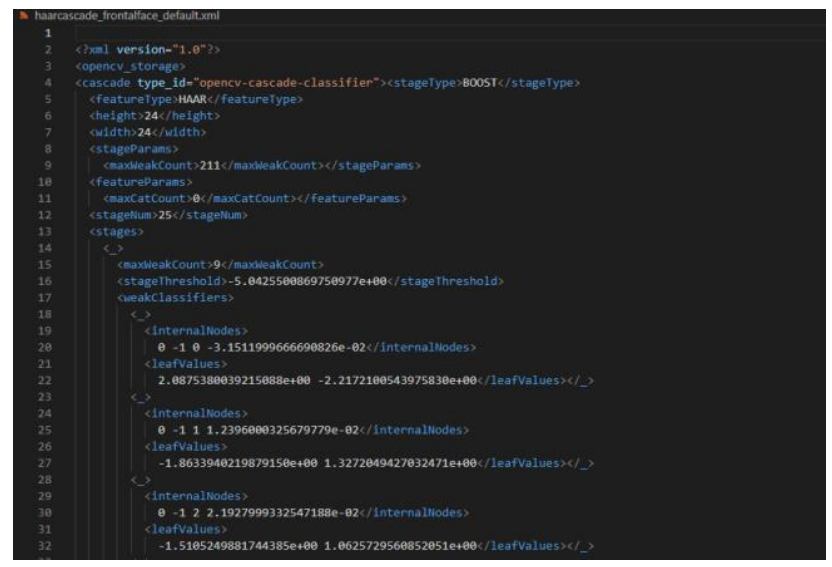

Fig. 6. Code Returned

In Fig.7 shows the images of the faces obtained which we declare the parameter to obtain the 300 images small size by capturing and then saved in a folder called faces so that the algorithm based on Machine Learning is trained using the tools of Flask and Python for a good training of the data [22].

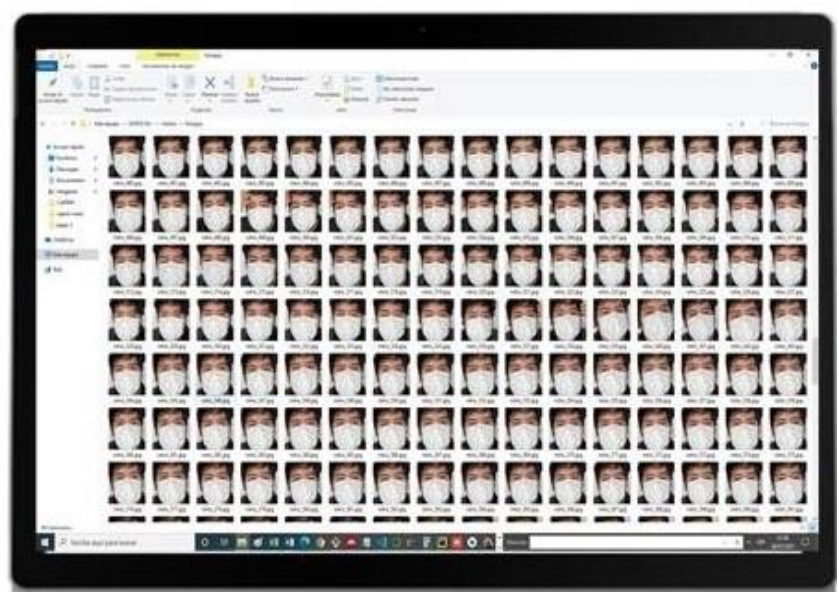

Fig. 7. Code capturing the face
In Fig. 8 the image shows the face prepared to be identified by the facial recognition system in order to obtain the features of the people and to provide a good quality service. In Fig.9 shows the face prepared to be identified by the facial recognition system.

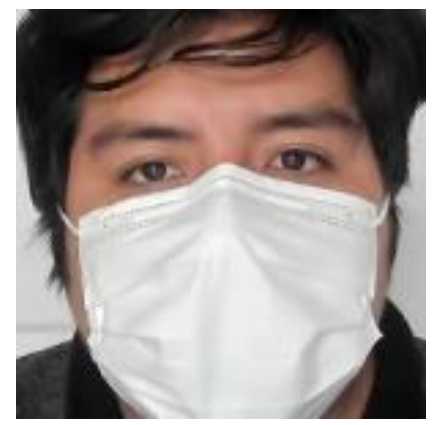

Fig. 8. Identified face

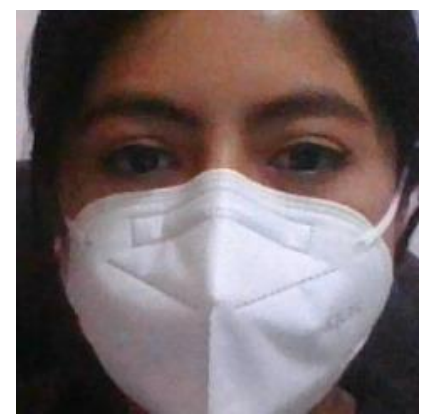

Fig. 9. Identified face

\section{E. Evaluate model}

In the fourth phase we evaluate and verify all the previous steps to give the approval for each of the procedures providing a good performance for facial recognition [23].

In Fig. 10 the whole process is shown in detail verifying each of the files created to see if there is no error with the code so that everything is ready and verified correctly so that it can be approved. 


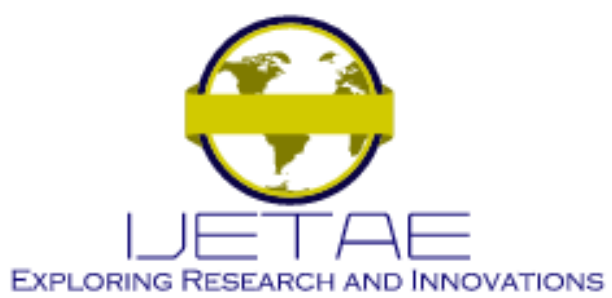

International Journal of Emerging Technology and Advanced Engineering Website: www.ijetae.com (E-ISSN 2250-2459, Scopus Indexed, ISO 9001:2008 Certified Journal, Volume 11, Issue 11, November 2021)

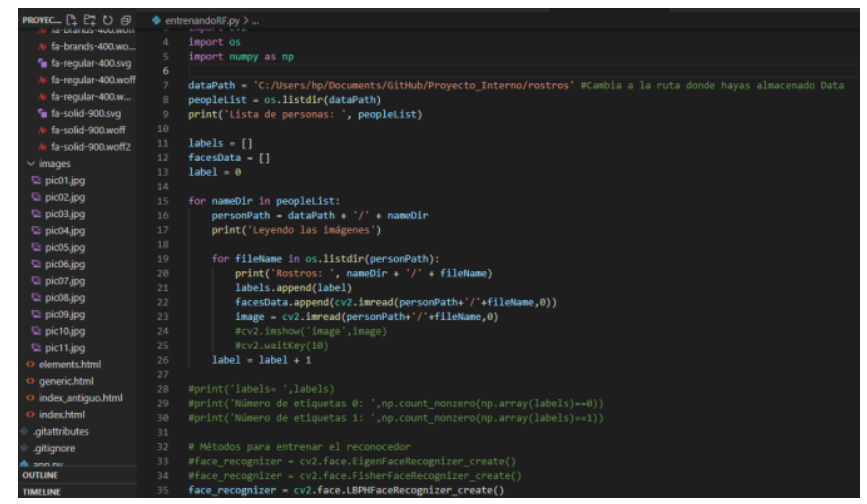

Fig. 10. Evaluate Model

\section{F. Results}

In the last phase we obtain the result by applying machine learning, the system was obtained by recognizing the face with mask in which all the phases mentioned above were performed in order to have a good control or planning of each phase or module established in addition to it also to recognize the face describes if the person is with mask.

\section{RESUlTS AND DisCUSSIONS}

\section{A. Entrance control to and entity}

With the passing of the years, facial recognition has become an object of inquiry worldwide, added to the progress of technology that is increasing more and more in such a way that significant advances have been achieved, therefore companies, whether public or private, use these face recognition systems in order to detect them in different spaces that they are in, With the spread of Covid-19, now that public or private places have been reactivated in different countries, it is mandatory to wear a face mask to reduce the contagion and at the same time take care of ourselves and our families. The contagion that can be caused in different places would be risky that is why we must maintain biosecurity to keep under control the contagion, the face recognition systems helps us and facilitates the good control of entry to an entity. When recognizing the face with a mask, half of the face is covered, so it is not possible to identify the person well, that is why it would be ideal to opt for the option of facial recognition.
In Fig. 11 shows another face identified in addition to this as a plus for the system also recognizes if the person is wearing the face mask correctly to avoid contagion among the staff.

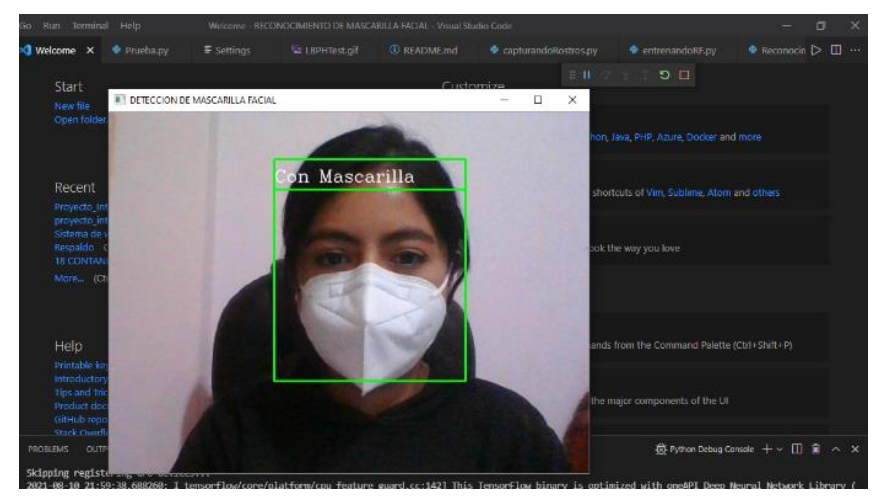

Fig. 11. Implementation of Machine Learning phases

\section{B. Risks}

In most countries around the world, different areas have already been reactivated because of the pandemic that came to a complete standstill, thus affecting the country with different factors such as the economy that was declining as a result of that, now that private and public services were reactivated some of the jobs are already in person where they require the person in person to perform the designated functions, so there are risks, now most people wear face masks and when entering their workplace must be recognized correctly as they could infiltrate people who do not work in the company taking advantage of wearing a face mask and can not be recognized in its entirety.

\section{Prevention}

The recognition helps today to identify people already in different spaces, in order to identify the person is why the implementation of facial recognition system would help many entities to prevent the risks that occur today.

\section{Security}

Security today is very important because we are not free from any incident that may occur, that is why we must identify our risks and analyze them based on this take preventive measures in order to have security in any entity where we are. 


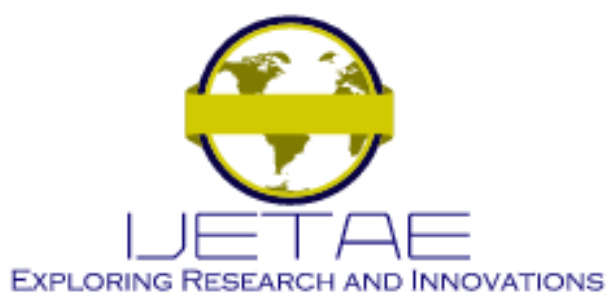

International Journal of Emerging Technology and Advanced Engineering Website: www.ijetae.com (E-ISSN 2250-2459, Scopus Indexed, ISO 9001:2008 Certified Journal, Volume 11, Issue 11, November 2021)

In Fig.12 shows the face completely identified by facial recognition, obtaining its name and a specification by 0 or 1 , thus recognizing the person by a number specific to each face so that it can return the name of each one.

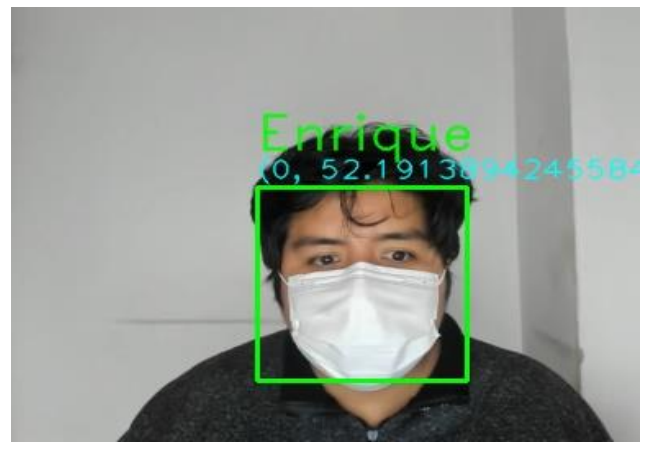

Fig. 12. Face identified with its respective name

In Fig.13 you can see the identified face shown above but as you can see it is now implemented in a server, besides that the page has different functions such as one of them is that you can take a picture and download it at the same time.

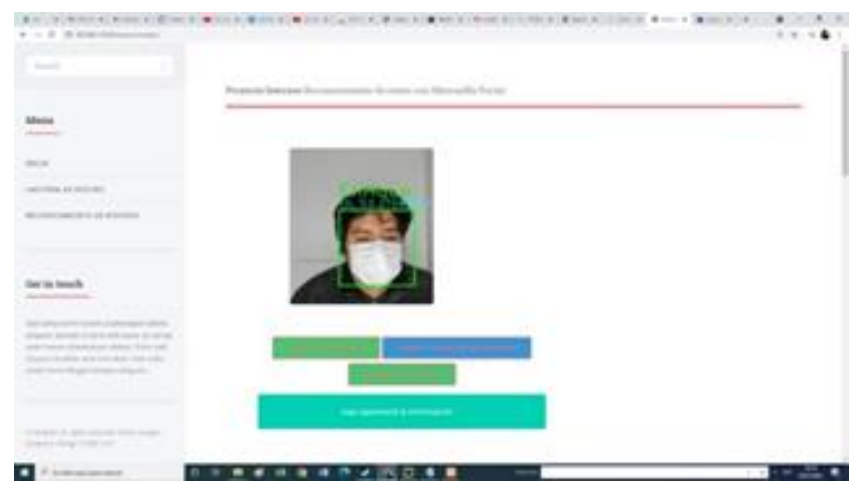

Fig. 13. Face identified with its respective name within a web service

\section{E. About the case Study}

For the case study, the use of artificial intelligence applied to face detection was carried out in 6 phases to have a good planning to apply it to the system as shown above in the phases carried out in the case study in detail.

\section{F. About the methodology}

Machine learning is a methodology adaptable to the system established by Artificial Intelligence, Machine Learning is a technology that helps many operations through specific algorithms required fulfilling its function by solving the need or problem of society. Maching learning also has different branches to choose the one that best suits the system by following the steps the machine has to be trained to provide truly satisfactory results.

1) Advantage: The advantage of using Machine Learning methodology is that it is easily adapted by algorithms to face detection with face mask, machine learning helps to solve problems that may occur in any circumstances.

2) Disadvantage: The main drawback of Machine Learning is that the program must be guided through all phases of the system so that it knows how to identify each category automatically, therefore, this modality requires supervised learning.

3) Comparison: Machine Learning uses algorithms to analyze data, learn from that data and make decisions based on what it learns. Deep Learning structures the algorithms in layers, to create an artificial neural network, which can learn and make decisions on its own.

\section{CONCLUSIONS}

In conclusion the use of artificial intelligence applied to face detection with face mask will help to have a good control in the entrance to an entity whether public or private because it can recognize the workers who work in their workplace in such a way that will immediately recognize the infiltrators who want to enter the company, the methodology used is machine learning which is very beneficial because when applying algorithms to the project we can choose to get a good result as it adapts to the system. With this implementation of the system for the detection of face identified with facial mask is intended that different companies of different items can opt for the detection of the face in such a way that will help in the control of entry to the entity established. 


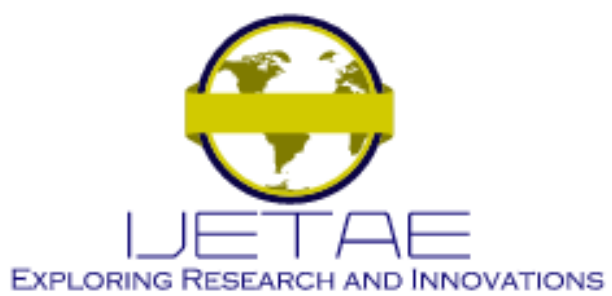

International Journal of Emerging Technology and Advanced Engineering

Website: www.ijetae.com (E-ISSN 2250-2459, Scopus Indexed, ISO 9001:2008 Certified Journal, Volume 11, Issue 11, November 2021)

\section{REFERENCES}

[1] Ciotti M, Ciccozzi M, Terrinoni A, Jiang WC, Wang CB, Bernardini S. The COVID-19 pandemic. Crit Rev Clin Lab Sci. 2020 Sep;57(6):365-388. doi: 10.1080/10408363.2020.1783198. Epub 2020 Jul 9. PMID: 32645276.

[2] Ali I, Alharbi OML. COVID-19: Disease, management, treatment, and social impact. Sci Total Environ. 2020 Aug 1;728:138861. doi: 10.1016/j.scitotenv.2020.138861. Epub 2020 Apr 22. PMID: 32344226; PMCID: PMC7175909.

[3] Wang, D., Hu, B., Hu, C., Zhu, F., Liu, X., Zhang, J., Wang, B., Xiang, H., Cheng, Z., Xiong, Y., Zhao, Y., Li, Y., Wang, X., \& Peng, Z. (2020). Clinical Characteristics of 138 Hospitalized Patients With 2019 Novel Coronavirus-Infected Pneumonia in Wuhan, China. JAMA, 323(11), 1061-1069. https://doi.org/10.1001/jama.2020.1585

[4] [4] Zhu N, Zhang D, Wang W, Li X, Yang B, Song J, Zhao X, Huang B, Shi W, Lu R, Niu P, Zhan F, Ma X, Wang D, Xu W, Wu G, Gao GF, Tan W; China Novel Coronavirus Investigating and Research Team. A Novel Coronavirus from Patients with Pneumonia in China, 2019. N Engl J Med. 2020 Feb 20;382(8):727-733. doi: 10.1056/NEJMoa2001017. Epub 2020 Jan 24. PMID: 31978945 ; PMCID: PMC7092803.

[5] Bhargava, A., Fukushima, E. A., Levine, M., Zhao, W., Tanveer, F., Szpunar, S. M., \& Saravolatz, L. (2020). Predictors for Severe COVID-19 Infection. Clinical infectious diseases : an official publication of the Infectious Diseases Society of America, 71(8), 1962-1968. https://doi.org/10.1093/cid/ciaa674.

[6] Wang, C. Z., Hu, S. L., Wang, L., Li, M., \& Li, H. T. (2020). Early risk factors of the exacerbation of coronavirus disease 2019 pneumonia. Journal of medical virology, 92(11), 2593-2599. https://doi.org/10.1002/jmv.26071

[7] Renu K, Prasanna PL, Valsala Gopalakrishnan A. Coronaviruses pathogenesis, comorbidities and multi-organ damage - A review. Life Sci. 2020 Aug 15;255:117839. doi: 10.1016/j.Ifs.2020.117839. Epub 2020 May 22. PMID: 32450165; PMCID: PMC7243768.

[8] Cirrincione, L., Plescia, F., Ledda, C., Rapisarda, V., Martorana, D., Moldovan, R. E., ... \& Cannizzaro, E. (2020). COVID-19 pandemic: Prevention and protection measures to be adopted at the workplace. Sustainability, 12(9), 3603.

[9] Sorto, A., Marquez, T., Carrasco, A., \& Ordoñez, J. (2020, November). Face Recognition and Temperature Data Acquisition for COVID-19 Patients in Honduras. In Journal of Physics: Conference Series (Vol. 1710, No. 1, p. 012009). IOP Publishing.

[10] Zhang, X. D. (2020). Machine learning. In A Matrix Algebra Approach to Artificial Intelligence (pp. 223-440). Springer, Singapore.
[11] Tasnim, Z., Javed Mehedi Shamrat, F. M., Allayear, S. M., Ahmed, K., \& Nobel, N. I. (2021). Implementation of an Intelligent Online Job Portal Using Machine Learning Algorithms. In Emerging Technologies in Data Mining and Information Security: Proceedings of IEMIS 2020, Volume 3 (pp. 591-603). Springer Singapore.

[12] Mahesh, B. (2020). Machine Learning Algorithms-A Review. International Journal of Science and Research (IJSR).[Internet], 9, 381-386.

[13] Charbuty, B., \& Abdulazeez, A. (2021). Classification based on decision tree algorithm for machine learning. Journal of Applied Science and Technology Trends, 2(01), 20-28.

[14] Green, B., \& Hu, L. (2018, July). The myth in the methodology: Towards a recontextualization of fairness in machine learning. In Proceedings of the machine learning: the debates workshop.

[15] Tang, J., Zheng, L., Han, C., Yin, W., Zhang, Y., Zou, Y., \& Huang, H. (2020). Statistical and machine-learning methods for clearance time prediction of road incidents: A methodology review. Analytic methods in accident research, 27, 100123.

[16] von Rueden, L., Mayer, S., Beckh, K., Georgiev, B., Giesselbach, S., Heese, R., ... \& Schuecker, J. (2019). Informed Machine Learning-A Taxonomy and Survey of Integrating Knowledge into Learning Systems. arXiv preprint arXiv:1903.12394.

[17] Rask, J. K., Madsen, F. P., Battle, N., Macedo, H. D., \& Larsen, P. G. (2021). Visual Studio Code VDM Support. John Fitzgerald, Tomohiro Oda, and Hugo Daniel Macedo (Editors), 35.

[18] A. Safari and A. A. Ghavifekr, "International Stock Index Prediction Using Artificial Neural Network (ANN) and Python Programming," 2021 7th International Conference on Control, Instrumentation and Automation (ICCIA), 2021, pp. 1-7, doi: 10.1109/ICCIA52082.2021.9403580.

[19] M. Lu and F. Li, "Survey on lie group machine learning," in Big Data Mining and Analytics, vol. 3, no. 4, pp. 235-258, Dec. 2020, doi: 10.26599/BDMA.2020.9020011.

[20] Huamaní, E. L., Condori, P., \& Roman-Gonzalez, A. Virtualizing a Cluster to Optimize the Problems of High Scientific Complexity within an Organization. vol, 10, 618-622.

[21] Huamaní, E. L., Condori, P., \& Roman-Gonzalez, A. (2019). Implementation of a Beowulf Cluster and Analysis of its Performance in Applications with Parallel Programming. Int. J. Adv. Comput. Sci. Appl, 10(8), 522-527.

[22] Huamaní, E. L., Condori, P., Meneses-Claudio, B., \& RomanGonzalez, A. Render Farm for Highly Realistic Images in a Beowulf Cluster using Distributed Programming Techniques.

[23] Jiang, M., Fan, X., \& Yan, H. (2020). Retinamask: A face mask detector. arXiv preprint arXiv:2005.03950. 